\title{
Length Scale and Aging Effect on the Mechanical Properties of a 63Sn-37Pb
} Solder Alloy

\author{
T. Jesse Lim; Wei-Yang Lu, Sandia National Laboratories, Livermore, CA.
}

The submitted manuscript has been authored by a contractor of the United States Government under contract. Accordingly the United States Gov. ernment retains a non-exclusive, royalty-free license to publish or ro produce the published form of this Abstract contribution, ox allow others to do so, for United States Covernment purs pases.

In this work, uniaxial tensile testing of a $63 \mathrm{Sn}-37 \mathrm{~Pb}$ alloy with different specimen sizes and aging conditions had been carried out. Although the stress-strain responses of different specimen sizes and aging conditions differs, the ultimate strength of the specimens with 16 hours, $100^{\circ} \mathrm{C}$ aging are similar for the sizes tested. The specimens with 25 days, $100^{\circ} \mathrm{C}$ aging have different stress-strain response with different sizes, and have a lower ultimate strength and higher failure strain compared to 16 hours, $100^{\circ} \mathrm{C}$ aging specimens.

\section{Introduction}

Surface mount technology of electronic components is becoming more popular to reduce the size of electronic packaging. In order to assess the reliability of the packaging, it becomes important to understand the thermal-mechanical properties of solder interconnects. Previously, all constitutive modeling of $\mathrm{SnPb}$ solder alloys was based on the thermal-mechanical testing of bulk material which is typically hundreds of times larger than the solder interconnects. As the size of solder interconnects becoming smaller and approaching similar length scale of the constituents particles (individual grains, size of different alloy phases), the thermal-mechanical properties may not resemble that of bulk scale [1]. Moreover, since room temperature is already a high homologous temperature for typical solder alloy, there is significant aging effect or grain coarsening during the service life of the electronic component. These effects may affect the thermal-mechanical properties of the solder interconnects even without repeated thermal or mechanical loading [2]. It is therefor important to study the mechanical properties of solder alloy with different sizes and different microstructures (results from various aging conditions). As a result, constitutive modeling of solders can also include parameters of length scale to better predict the reliability of solder interconnects.

\section{Specimen preparation and testing}

The solder alloy under this study is a $63 \mathrm{Sn}-37 \mathrm{~Pb}$ alloy in solid wire form supplied by Kester Solder. Specimens of various sizes were fabricated by casting. All specimens were made with a circular cross section with three different diameter sizes: 1) $6.35 \mathrm{~mm}$; 2) $1.0 \mathrm{~mm}$; and 3)0.35mm. The gage length of each specimen was made the same as the diameter size such that all specimens have a same geometry.

Figure 1 shows the casting mold for the $1 \mathrm{~mm}$ specimen. Two brass rods were clamped to both ends of the aluminum mold. The mold was heated to $200^{\circ} \mathrm{C}$, above the melting point of $\mathrm{Pb}-\mathrm{Sn}$ solder which permits flowing the molten alloy into it. The mold was then cooled at a rate about $10^{\circ} \mathrm{C} / \mathrm{min}$, and the $\mathrm{SnPb}$ alloy solidified. The specimen, solder with brass ends, was released from the mold and transferred to a fixture, which prevents solder from deforming during 


\section{DISCLAIMER}

This report was prepared as an account of work sponsored by an agency of the United States Government. Neither the United States Government nor any agency thereof, nor any of their employees, make any warranty, express or implied, or assumes any legal liability or responsibility for the accuracy, completeness, or usefulness of any information, apparatus, product, or process disclosed, or represents that its use would not infringe privately owned rights. Reference herein to any specific commercial product, process, or service by trade name, trademark, manufacturer, or otherwise does not necessarily constitute or imply its endorsement, recommendation, or favoring by the United States Government or any agency thereof. The views and opinions of authors expressed herein do not necessarily state or reflect those of the United States Government or any agency thereof. 


\section{DISCLAIMER}

Portions of this document may be illegible in electronic image products. Images are produced from the best available original document. 
handling and kept the assembly aligned. The solder assembly was placed in the oven for aging treatments to produce the desired microstructures. In the present study, two different aging treatments were used: 1) 16 hours in $100^{\circ} \mathrm{C}$ atmospheric air $(16 \mathrm{H})$; and 2) 25 days in $100^{\circ} \mathrm{C}$ atmospheric air (25D).

Uniaxial tensile tests using a MTS Tytron microforce testing system were performed on specimens with sizes $1.0 \mathrm{~mm}$ and $0.35 \mathrm{~mm}$ in diameter. Figure 2 shows the test setup, the two brass ends were attached to the load cell and the actuator of the Tytron loading frame, respectively. An extensometer was attached to the specimen for recording the strain at the gage section. The $6.35 \mathrm{~mm}$ specimens were tested by conventional MTS servo-hydraulic loading frame since the failure strength of $6.35 \mathrm{~mm}$ specimens far exceed the loading capacity of the Tytron system. A ramp function was applied to the displacement of the actuator such that the approximate strain rate at the gage section was $10^{-4} / \mathrm{s}$. All uniaxial tests were conducted in room temperature and run until the specimen failed. Three specimens were tested for each heat treatment and each size to ensure repeatability of test results.

\section{Results and discussion}

The stress-strain responses of specimen 2 from each size and each heat treatment were plot in Figure 3 for comparisons. All stress-strain curves have an initial elastic response, flat out with the ultimate strength and then following a rather constant strain softening rate until failure. Table 1 summarize the ultimate strength $\left(\sigma_{\mathrm{u}}\right)$ and failure strain $\left(\varepsilon_{\mathrm{f}}\right)$ for each specimen. In both Figure 3 and Table 1, specimen size is the specimen diameter in the gage section.

The results are preliminary. However, some trend can still be observed from all $1.0 \mathrm{~mm}$ and $0.35 \mathrm{~mm}$ specimens. In general, the specimens subjected to $25 \mathrm{D}$ aging have a lower $\sigma_{\mathrm{u}}$ and a less negative strain softening rate beyond yielding. And for $1 \mathrm{~mm}$ specimens, $\varepsilon_{\mathrm{f}}$ is larger for $25 \mathrm{D}$ specimens than that of $16 \mathrm{D}$ specimens, however, this trend is not obvious for $0.35 \mathrm{~mm}$ specimens.

It is then necessary to study the microstructure of specimens with different aging to draw a qualitative analysis of these observed trends. Here, we will study one $1 \mathrm{~mm}$ specimen each of $16 \mathrm{H}$ and $25 \mathrm{D}$ aging. Figures $4 \mathrm{a}$ and $4 \mathrm{~b}$ are scanning electron microscopy (SEM) image of the fracture surfaces of one $16 \mathrm{H}$ specimen and one $25 \mathrm{D}$ specimen normal to the axial loading direction, respectively. Obviously, both fracture surfaces reveal that the fracture is ductile in nature, and since the strain to failure $\varepsilon_{\mathrm{f}}$ for the $25 \mathrm{D}$ specimen is larger, there is a further reduction in final fracture area.

We can then focus on one small area to investigate the fracture mechanism. Figures $5 \mathrm{a}$ and $5 \mathrm{~b}$ both show the high magnification SEM image on a same area of a 25D specimen. Figure 5a is a normal scanning while Figure $5 b$ is a back-scattered scanning which better reveals the chemical composition, dark area corresponds to $\mathrm{Sn}$-rich phase and bright area corresponds to $\mathrm{Pb}$-rich phase. Figures 5a shows various fracture lines, and for the corresponding places in Figure 5b, these fracture lines usually occurred between $\mathrm{Sn}$-rich and $\mathrm{Pb}$-rich phases. We can conclude that fracture occurs along the interface between $\mathrm{Sn}$-rich and $\mathrm{Pb}$-rich phases. Figures $6 \mathrm{a}$ and $6 \mathrm{~b}$ are SEM back-scattered images of one $16 \mathrm{H}$ and one $25 \mathrm{D}$ specimens respectively, which reveal the 
composition of $\mathrm{Sn}$ - or $\mathrm{Pb}$-rich phases. Obviously, the $25 \mathrm{D}$ aging have a coarser microstructure. A coarser microstructure will have a lower interfacial energy as well as mismatch stress and strain among different phases. Their effects on the macroscopic mechanical response will require further study [3].

\section{Conclusions and Future Works}

In this work, uniaxial tensile testing have been performed on a $63 \mathrm{Sn}-37 \mathrm{~Pb}$ solder alloy with various sizes and microstructures. The effect on size, or length scale on the ultimate strength is not obvious, though the failure strain differs. In general, the specimens having coarser microstructures had lower ultimate strengths and higher failure strains.

In order to make the testing and hence the constitutive modeling more complete, experiments have to be done under different temperature, specimen geometry and different mode of loading (e.g. torsion), with specimens of different sizes and aging treatments.

\section{References}

1. Bonda, N.R. and Noyan, I.C., "Effect of the Specimen Size in Predicting the Mechanical Properties of PbSn Solder Alloys," IEEE Transactions on Components, Packaging, and Manufacturing Technology---Part A, V.19, \#2, p.208-212, 1996.

2. Vianco, P.T., Burchett, S.N., Neilsen, M.K., Rejent, J.A. and Frear, D.R., "Coarsening of the $\mathrm{Sn}-\mathrm{Pb}$ Solder Microstructure in Constitutive Model-Based Predictions of Solder Joint Thermal Mechanical Fatigue," Journal of Electronic Materials, V.28, \#11, p.1290-1298, 1999.

3. Dreyer, W. and Müller, W.H., "A Study of the Coarsening in Tin/Lead Solders," International Journal of Solids and Structures, V.37, p.3841-3871, 2000.

\begin{tabular}{|c|c|c|c|c|c|c|c|}
\hline \multicolumn{2}{|c|}{} & \multicolumn{2}{c|}{ Specimen 1 } & \multicolumn{2}{c|}{ Specimen 2 } & \multicolumn{2}{c|}{ Specimen 3 } \\
\hline $\begin{array}{c}\text { Size } \\
(\mathrm{mm})\end{array}$ & Aging & $\begin{array}{c}\sigma_{\mathrm{u}} \\
(\mathrm{MPa})\end{array}$ & $\varepsilon_{\mathrm{f}}$ & $\begin{array}{c}\sigma_{\mathrm{u}} \\
(\mathrm{MPa})\end{array}$ & $\varepsilon_{\mathrm{f}}$ & $\begin{array}{c}\sigma_{\mathrm{u}} \\
(\mathrm{MPa})\end{array}$ & $\varepsilon_{\mathrm{f}}$ \\
\hline 6.35 & $16 \mathrm{H}$ & 40.0 & 0.29 & 45.0 & 0.31 & 41.0 & 0.23 \\
\hline 1.0 & $16 \mathrm{H}$ & 42.5 & 0.63 & 40.7 & 0.66 & 41.0 & 0.58 \\
\hline 1.0 & $25 \mathrm{D}$ & 37.4 & 0.73 & 35.4 & 0.80 & 35.5 & 0.74 \\
\hline 0.35 & $16 \mathrm{H}$ & 41.1 & 0.67 & 41.3 & 0.75 & 43.2 & 0.52 \\
\hline 0.35 & $25 \mathrm{D}$ & 39.9 & 0.46 & 38.7 & 0.69 & 34.8 & 0.63 \\
\hline
\end{tabular}

Table 1 Summary of test results of various specimens. Where sizes are specimen gage diameter. For aging, $16 \mathrm{H}=16$ hours in $100^{\circ} \mathrm{C}$ atmospheric air; $25 \mathrm{D}=25$ days in $100^{\circ} \mathrm{C}$ atmospheric air. 


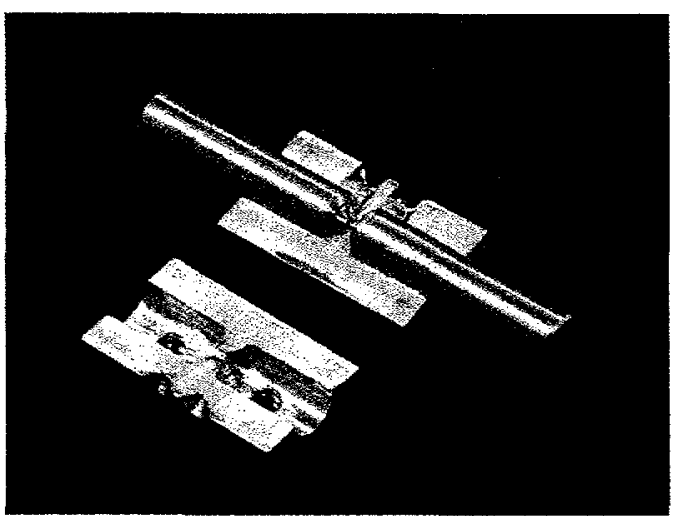

Figure 1 Specimen mold and brass ends for casting PbSn alloy specimens.

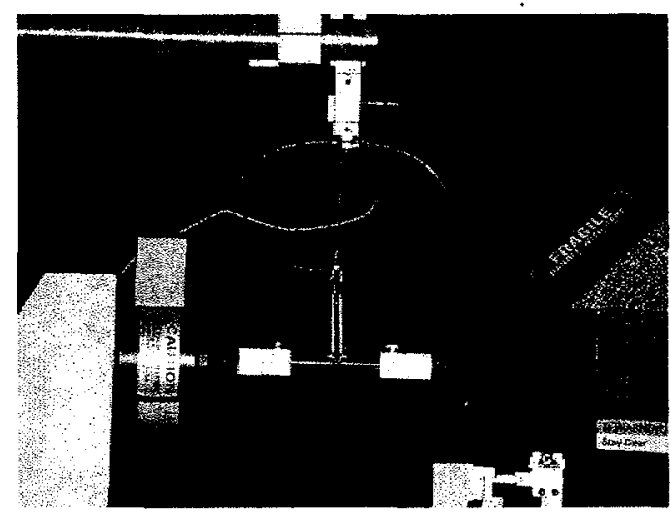

Figure 2 Specimen as mounted on MTS Tytron loading frame.

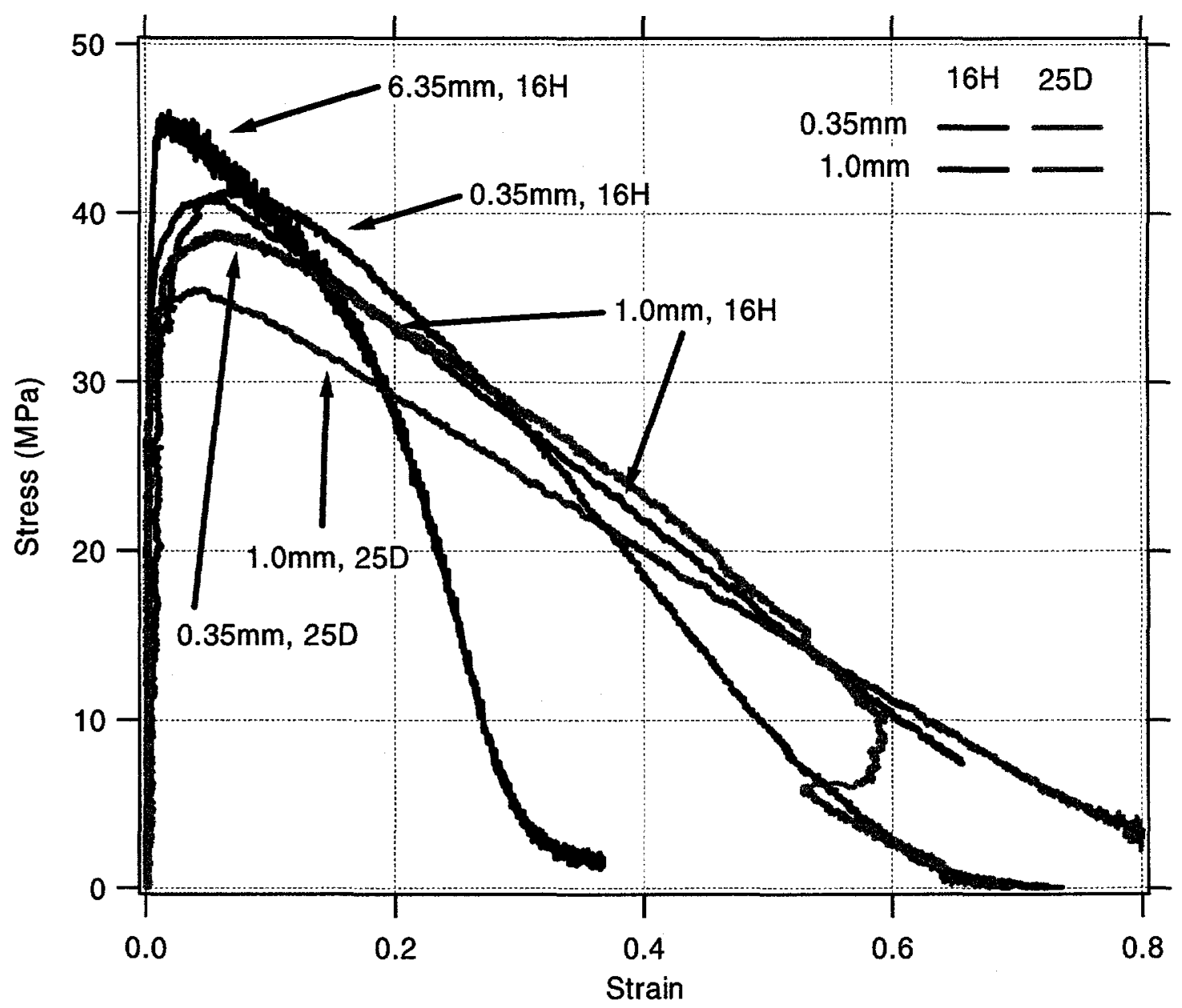

Figure 3 Stress-strain curves of various representative specimens with different sizes and heat treatments. 


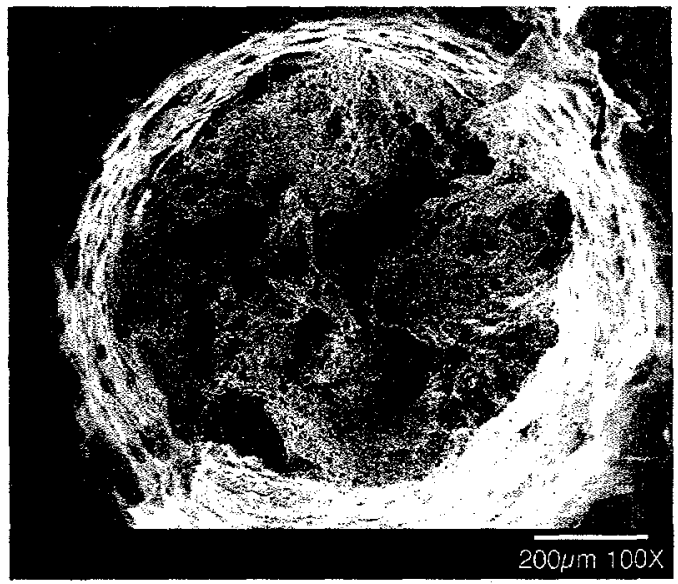

Figure 4a SEM image of fracture surface of a $1 \mathrm{~mm}, 16 \mathrm{H}$ specimen, viewing normal to the axial loading direction.

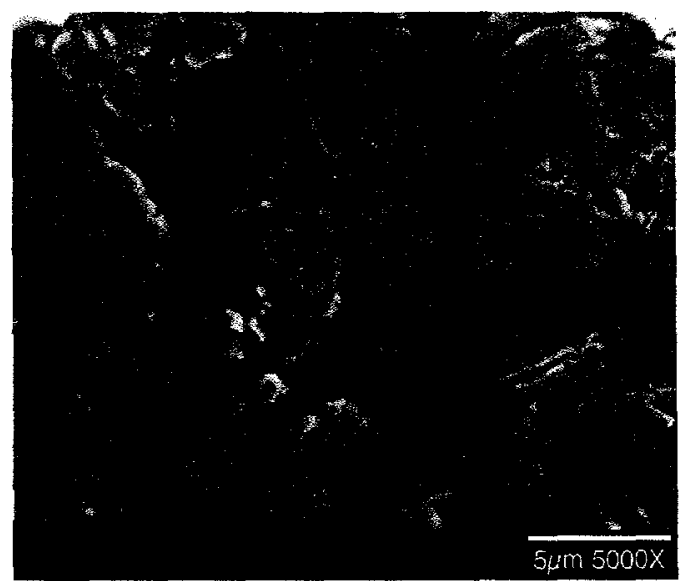

Figure 5a SEM image of a 1mm, 25D specimen, showing physical feature of a fracture site.

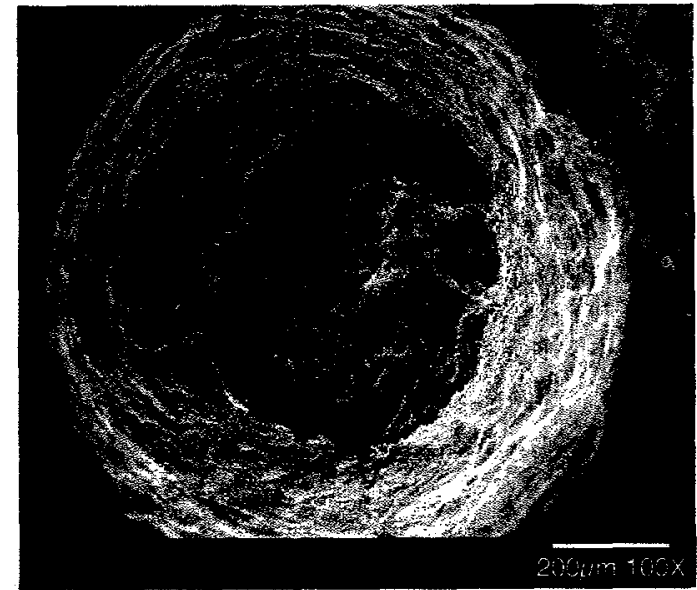

Figure 4b SEM image of fracture surface of a $1 \mathrm{~mm}, 25 \mathrm{D}$ specimen, viewing normal to the axial loading direction.

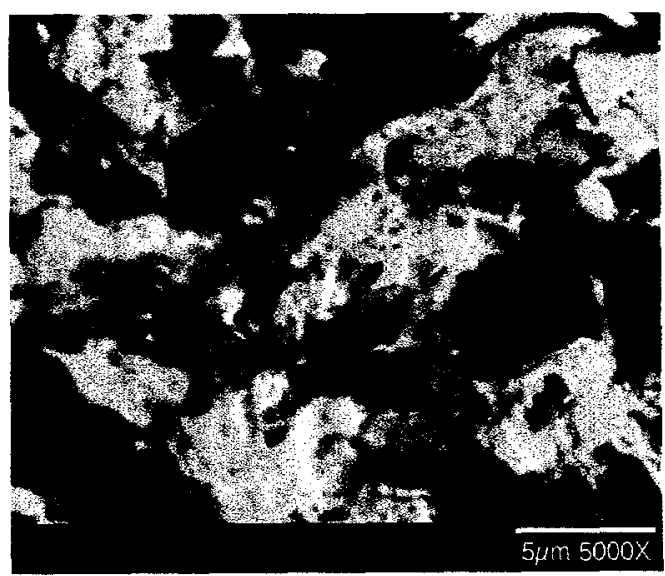

Figure 5b Back-scattered SEM image of a $1 \mathrm{~mm}, 25 \mathrm{D}$ specimen, showing different $\mathrm{Sn}$ - or $\mathrm{Pb}$-rich phases at a fracture site. 


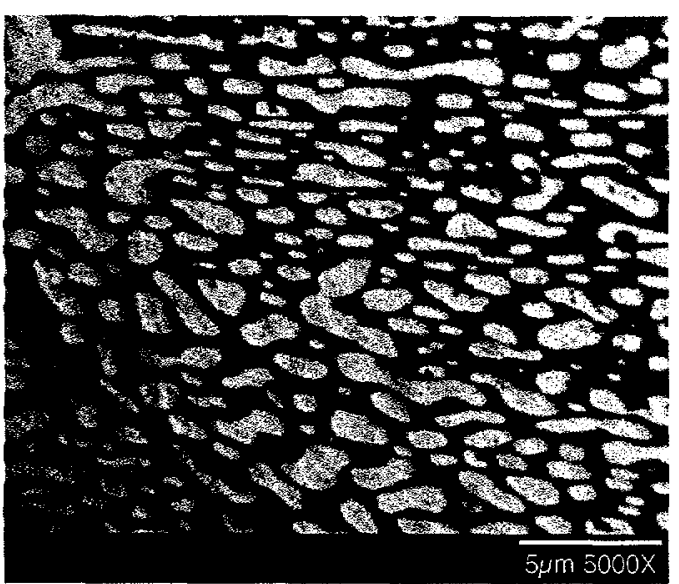

Figure 6a Back-scattered SEM image showing different phases of a $1 \mathrm{~mm}, 16 \mathrm{H}$ specimen.

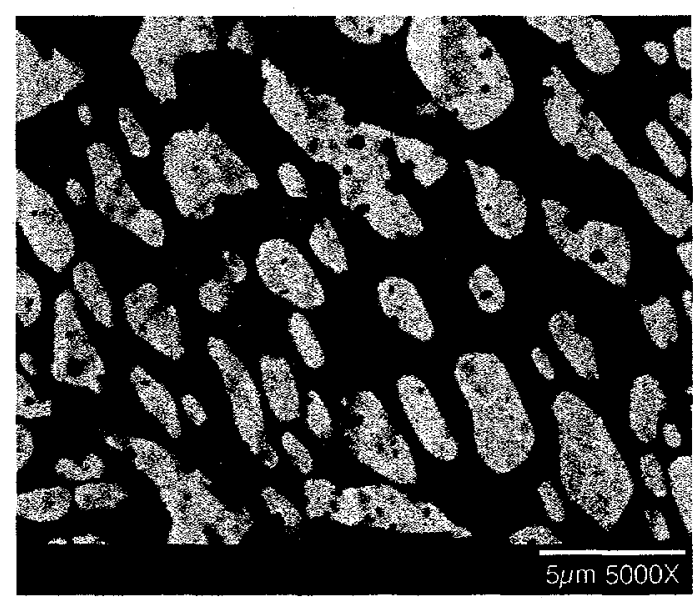

Figure 6b Back-scattered SEM image showing different phases of a $1 \mathrm{~mm}, 25 \mathrm{D}$ specimen. 